Viso - Cadernos de estética aplicada Revista eletrônica de estética

ISSN 1981-4062

No 16, jan-jun/2015

http://www.revistaviso.com.br/

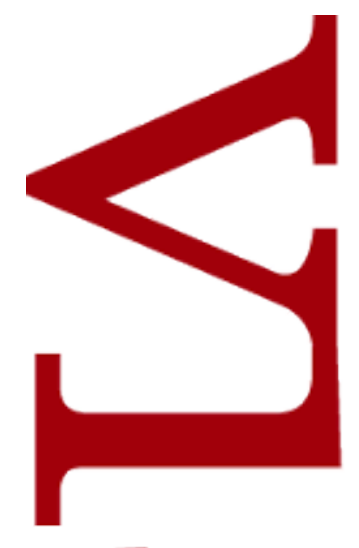

http.//www.revistaviso.com.br/
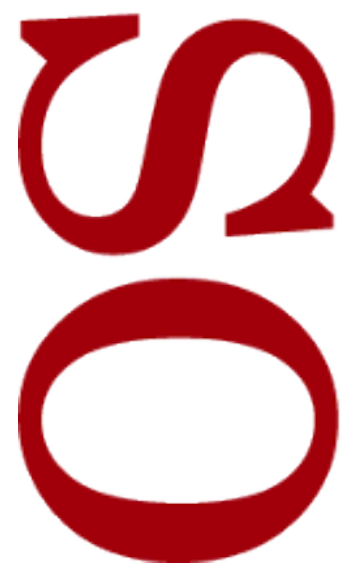

\title{
O problema da estética em Arthur Danto e a questão da crítica em Walter Benjamin \\ Rizzia Rocha
}




\section{RESUMO}

O problema da estética em Arthur Danto e a questão da crítica em Walter Benjamin

Diante das mudanças ocorridas na arte das últimas décadas, os critérios estéticos tradicionais perdem sua eficácia para pensar a produção artística contemporânea. Consequentemente, a recepção da obra de arte, assentada na tradição, torna-se inócua. Neste artigo apresento a necessidade de uma reconfiguração da recepção do objeto artístico a partir da crítica não normativa da obra de arte, cunhada por Walter Benjamin, em associação às reflexões sobre estética e filosofia da arte desenvolvidas por Arthur Danto. A aproximação entre esses dois autores, embora mantenha uma dimensão controversa, propõe rearticular aspectos do pensamento benjaminiano sobre a arte, corroborando sua crítica ao ideal forjado pela razão iluminista. Assim, o presente artigo expõe o problema da estética e da história partindo do olhar que o contemporâneo lança ao passado, o qual ressignifica importantes modificações que o século XVIII introduziu no conceito de arte.

Palavras-chave: estética - filosofia da arte - arte - recepção - crítica

\section{ABSTRACT}

The Problem of Aesthetics in Arthur Danto and the Issue of Criticism in Walter Benjamin

In the face of the changes in art along the recent decades, the traditional aesthetic criteria lose their effectiveness to think the contemporary artistic production. Consequently, the art reception, based upon tradition, becomes innocuous. In this article I present the need for reconfiguration of the art reception from the non-normative critical work of Walter Benjamin, in association with reflections on aesthetics and philosophy of art developed by Arthur Danto. The approach of these two authors, while maintaining a controversial dimension, proposes to reorganize aspects of Benjamin's thinking about art, supporting its criticism of the ideal forged by Enlightenment reason. Thus, this article presents the problem of aesthetics and history starting from the look that contemporanity launches to the past, which reframes the major changes that the eighteenth century introduced in the concept of art.

Keywords: aesthetics - philosophy of art - art - reception - criticism 
ROCHA, R. "O problema da estética em Arthur Danto e a questão da crítica em Walter Benjamin". In: Viso: Cadernos de estética aplicada, v. IX, n. 16 (jan-abr/2015), pp. 45-54.

DOI: $10.22409 / 1981-4062 / v 16 i / 195$

Aprovado: 22.07.2015. Publicado: 30.07.2015.

(C) 2015 Rizzia Rocha. Esse documento é distribuído nos termos da licença Creative Commons Atribuição-NãoComercial 4.0 Internacional (CC-BY-NC), que permite, exceto para fins comerciais, copiar e redistribuir o material em qualquer formato ou meio, bem como remixá-lo, transformá-lo ou criar a partir dele, desde que seja dado o devido crédito e indicada a licença sob a qual ele foi originalmente publicado.

Licença: http://creativecommons.org/licenses/by-nc/4.0/deed.pt_BR

Accepted: 22.07.2015. Published: 30.07.2015.

(C) 2015 Rizzia Rocha. This document is distributed under the terms of a Creative Commons Attribution-NonCommercial 4.0 International license (CC-BY-NC) which allows, except for commercial purposes, to copy and redistribute the material in any medium or format and to remix, transform, and build upon the material, provided the original work is properly cited and states its license.

License: http://creativecommons.org/licenses/by-nc/4.0/ 
No lluminismo uma ideia de arte foi formada a partir de uma validade atemporal e universal cuja sustentação é carente de uma estrutura histórica superior ao tempo individual das obras. Surge, portanto, um conceito de arte que se pretende universal, o qual é urdido por uma história da arte cujo pretenso universalismo se constitui à custa de muitas omissões e exclusões. Essa época coincide com a criação dos museus, espaços responsáveis por encerrar as produções artísticas, retirando-as da vida cotidiana. Essa abstração iniciada no século XVIII, evento simultâneo à criação da estética como disciplina, dá à arte um conteúdo intelectual próprio e, ironicamente, quase autônomo, pois esse conteúdo é, em muitos casos, independente das obras. Nesse cenário repercute o que escreve Friedrich Schlegel em 1797: "naquilo que chamamos de filosofia da arte, habitualmente falta uma ou outra: ou a filosofia, ou então a arte". ${ }^{1}$ Passados dois séculos em que a história da arte se constituiu como história estético-normativa de pretensões universais, Marcel Duchamp dá início a um processo de desmaterialização do objeto artístico como objeto estético. A restrição da arte à beleza, escreve Danto em O descredenciamento filosófico da arte, fez da obra objeto estético subtraído da vida efetiva e isolado por uma aura cerimonial devotada à contemplação e à fruição. Esse liame estético entre arte e beleza, escreve o filósofo estadunidense, foi uma estratégia filosófica com importantes implicações políticas, pois transformar a arte em um mero objeto estético debilita sua força de ação no mundo. Atitude semelhante acontece ao qualificar a mulher de belo sexo, pois isso retira sua capacidade de atuar na vida prática como indivíduo cujas soluções e decisões interferem objetivamente no mundo. Em salas confortáveis, as mulheres praticavam ações sem finalidade prática, as quais se assemelhavam ao trabalho - tais como bordar, pintar aquarelas, ler - para servir ao deleite do opressor. ${ }^{2}$ Assim, escreve Danto, as belas artes, separadas das artes práticas, são "uma espécie de lugar ontológico vago de nossas preocupações definitórias como seres humanos e com respeito às quais, consequentemente, 'nada faz acontecer'”. ${ }^{3}$ Por isso a afirmação de Duchamp: "o perigo a ser evitado é o deleite". ${ }^{4}$

A tradição estética se revela como um modo de impor limites que debilitam a arte. Esse descredenciamento é preparado pela filosofia desde Platão que, tendo consciência dos poderes da poesia, exclui os poetas do Estado. "Desde então, a questão do direito à existência do poeta raramente tem sido colocada com essa ênfase; mas ela se coloca hoje. [... Essa questão é] familiar sob a forma do problema da autonomia do autor: sua liberdade de escrever o que quiser", declara Benjamin em sua conferência "O autor como produtor"s pronunciada em 1934. A autonomia restrita reverbera no lamento de Auden: "a história política do mundo seria a mesma se nenhum poema tivesse sido escrito, nenhum quadro pintado, nenhum compasso composto". ${ }^{6}$ Impotentes diante da efetividade do mundo, os artistas se tornam seres aureolados que se alimentam de quintessências e vivem o dom de produzir coisas belas. Essa é a imagem do artista satirizada por Charles Baudelaire em seu poema em prosa "Perda da auréola". Nele, um poeta, ao atravessar a rua, é surpreendido por uma carruagem e, correndo para não ser atropelado pelos cavalos, perde sua auréola que cai na lama. Sem o acessório estético que lhe dava a aparente dignidade de poeta, ele pode passear incógnito, praticar ações baixas, 
entregar-se à devassidão como um simples mortal. ${ }^{7} \mathrm{~A}$ imagem baudelairiana desse artista de aspecto comum é também a imagem da obra de arte que os meios técnicos de reprodução tornam ordinária. A repetição cotidianiza as obras dispersando sua aura cerimonial ao oferecê-las aos olhos do observador nos lugares mais corriqueiros da cidade.

Nessa atmosfera, $A$ fonte de Duchamp surge com o intuito de desagregar a objetificação estética da arte. É importante notar que a presença do feio na arte, como bem coloca Danto, não nos retira do campo estético, pois tratando de feiura ou beleza a objetificação é preservada. Assim, existem dois momentos distintos nesse processo: a desvinculação da estética do conceito de beleza e a desvinculação entre arte e experiência estética. ${ }^{8}$ Os readymades são esses objetos inestéticos que lançam a produção artística em um espaço discursivo no qual se torna prática comum, e muitas vezes imprescindível, a apresentação, junto à obra, de textos de conteúdo descritivo, político, crítico, a fim de contextualizar um objeto cuja oferta de estímulos ao aparelho sensorial do observador é, muitas vezes, pequena ou mesmo nula. $O$ discurso institucionalizado enfraquece diante das muitas práticas artísticas que buscam uma reintegração à vida cotidiana e ganham cada vez mais visibilidade em espaços alternativos. Embora a arte se presentifique como processo imerso em um contexto sócio-histórico-cultural, e em certa medida seja definida por ele, o discurso artístico ainda é dominado por conceitos absolutos que envolvem a arte numa aura metafísica descredenciando-a do mundo efetivo.

A distinção entre uma ideia de arte que se constitui como matéria para uma história normativa da arte $^{9}$ e a produção artística como parte das manifestações culturais e, portanto, tão plural como são as várias culturas, modifica o modo de apreensão da obra de arte singular habituado ao conceito de arte como objeto estético segregado da vida. Essas mudanças criaram uma extrema instabilidade dos padrões perceptivos, tornaram o julgamento precaríssimo e tiraram da noção de obra de arte sua unicidade específica ${ }^{10}$, escreve de maneira perspicaz o crítico Mario Pedrosa em um texto de 1959. Essa instabilidade abre caminho para uma reflexão autocrítica da produção, recepção e lugar social da arte exigindo uma nova configuração das relações de conhecimento. A postura passiva sustentada pelo espectador em estado de contemplação ou fruição pouco ou nada favorece a apreensão de obras esteticamente banais. Esse observador passivo deve dar lugar ao observador ativo que tem diante de si não um objeto à espera de um juízo, mas uma obra incompleta que se perfaz no trabalho da recepção. A obra de arte exibe de maneira patente seu caráter de inacabamento convidando a leituras que a intensifiquem, desdobrem, atualizem.

A crítica, ação que se configura menos como o julgamento da obra que como método de seu acabamento", "inclui o conhecimento de seu objeto. Daí por que a exposição do conceito primeiro romântico de crítica de arte exige uma caracterização da teoria do conhecimento do objeto que está em sua base..12 Assim, apresentando em linhas gerais a teoria benjaminiana do conhecimento, o filósofo empreende uma reabilitação do 
conceito de experiência, causa primordial de sua crítica à epistemologia kantiana ${ }^{13}$, procurando dissolver a dicotomia sujeito-objeto responsável pelo empobrecimento do conceito de experiência. Ao procurar neutralizar essa polarização, Benjamin se afasta da ideia de um objeto passivo à ação perceptiva de um sujeito e, desse modo, é possível associar a essa noção uma crítica ao pensamento positivista, e sua pressuposição comum de que o objeto não interfere nas relações de conhecimento. Portanto, quando surge a denominação objeto de arte neste artigo, ele deve ser compreendido como descreve Jorge Coli em seu livro $O$ corpo da liberdade, a saber, como "materialização de um pensamento no mundo que não encontra equivalente nas formulações abstratas". ${ }^{14}$ No trabalho de ressignificação, o conceito de experiência é caracterizado na linguagem. $\mathrm{Na}$ arquitetônica do pensamento benjaminiano, experiência é linguagem e a reflexão o lugar do conhecimento.

Em sua dissertação sobre os românticos, Benjamin descreve a crítica como processo gnosiológico cuja base está na reflexão. A reflexão encerra todo o conhecimento em geral. Nela o pensamento se volta sobre si mesmo tomando sua forma como seu conteúdo, o pensar como forma do pensar. Nesse processo, a essência pensante, segundo Novalis, envolta em sua "si-mesmidade é o fundamento de todo o conhecimento"..$^{15}$ Assim, escreve Benjamin sobre os românticos, não é possível conhecimento para além do autoconhecimento, ou dito de outra maneira, não há conhecimento fora do sujeito, todo conhecimento é um nexo imanente no sujeito sendo cada coisa uma essência pensante ou núcleo de reflexão. Essa ideia dissolve a polarização entre sujeito e objeto ao mesmo tempo em que traz o problema de encerrar o sujeito no isolamento de uma singularidade extrema. A resposta a essa questão está no medium de reflexão, nele "a coisa e a essência cognoscente se interpenetram". ${ }^{16} \mathrm{O}$ medium pode ser compreendido como o lugar onde jazem, sem qualquer ordem relacional, os núcleos de reflexão, ou seja, podemos tomar por medium o mundo onde tudo o que é efetivo repousa. ${ }^{17} \mathrm{Nele}$, as conexões são livremente urdidas engendrando conhecimento do mundo no autoconhecimento e autoconhecimento no conhecimento do mundo. "Não há, de fato, conhecimento de um objeto através de um sujeito. Todo conhecimento é um nexo imanente [...] no sujeito". ${ }^{18}$ E são infinitas as possibilidade de conexão promanadas no processo reflexivo em que as coisas se agrupam e reagrupam formando novos arranjos. Se os românticos centralizam o processo de reflexão no objeto, "tudo o que está no absoluto, toda a efetividade pensa" ${ }^{19}$, e Fichte o centraliza no eu-absoluto, Benjamin opta por conservar uma tensão ao invés de resolver o problema do conhecimento atribuindo maior responsabilidade no processo a um único polo. Benjamin localiza a ação do conhecimento no âmbito intersubjetivo sustentado por uma tensão entre os elementos, o que não pressupõe um processo cognitivo aleatório e meramente subjetivo.

O objeto de arte, nesse contexto, traz inscrito o seu germe crítico, no qual está a potência de associações, de leituras capazes de intensificar, desdobrar, atualizar a obra integrando sua singularidade ao todo da arte. Em sua tese, Benjamin cita o famoso 
fragmento de F. Schlegel, "apenas o incompleto pode ser compreendido, pode nos levar mais além. O completo pode ser apenas desfrutado". ${ }^{20}$ A concepção de uma obra incompleta, que tem no processo crítico de recepção o seu acabamento, compreende a produção artística como projeto. Nesse sentido, a crítica é a consumação das obras, pois ela destrói a aparência de completude do objeto artístico, exibindo o seu caráter fragmentário.

A crítica produtiva, necessária à mudança do modo de apreensão da obra na arte contemporânea, questiona o estatuto da arte em meio à experimentação, liberdade e democratização. No entanto, nesse contexto livre dos limites tradicionais, é comum encontrarmos um público perdido e uma crítica detida em compor e/ou exaltar a figura do artista, mas que pouco ou nada diz a respeito das obras de arte. A compreensão da arte como um processo que se perfaz na recepção crítica faz da reflexão o fulcro no qual a obra tem seu desdobramento produtivo. Cabe ressaltar, se ainda não está claro, que a crítica benjaminiana não é normativa, prescindindo, portanto, de critérios estéticos a priori para a avaliação das obras. Segundo Benjamin, é no germe crítico, inerente à obra de arte, que consiste a potência de seu desdobramento interpretativo. A obra de arte não se restringe a um objeto estético que deva ser avaliado por critérios perceptuais. A contemporaneidade evidencia a estética como elemento de segunda ordem na apreensão do objeto artístico e Arthur Danto explicita essa mudança em A transfiguração do lugar comum. Nesse trabalho o valor da percepção estética é amplamente discutido ao tratar o problema das obras de arte indiscerníveis de meros objetos, como o caso da Brillo Box, o exemplo recorrente do autor. Ao tratar a questão, Danto indaga as bases ontológicas da arte procurando pensá-las além da conformação estética. Ele argumenta que "existem duas ordens de reações estéticas, dependendo de o objeto ser uma obra de arte ou uma simples coisa real idêntica". ${ }^{21}$ Portanto, existem qualidades estéticas e qualidades artísticas, as quais, segundo Danto, não são equivalentes.

Pensemos, então, no exemplo trazido pelo próprio Danto em seu livro O abuso da beleza, Untitled (Perfect Lovers), obra do artista cubano Félix Gonzalez-Torres, e nas reações perceptivas que a visão dos relógios nos provoca, pois a obra consiste em dois relógios de parede comuns postos lado a lado. Esses relógios, perfeitamente iguais, são alimentados com o mesmo tipo de bateria e sincronizados. Por razões indeterminadas um dos relógios irá interromper seu funcionamento antes do outro. O artista expõe essa obra logo após a morte de seu namorado e podemos afirmar que as reações suscitadas por ela diferem daquelas incitadas por relógios de parede quaisquer, embora as características sensoriais desses artefatos sejam as mesmas. 


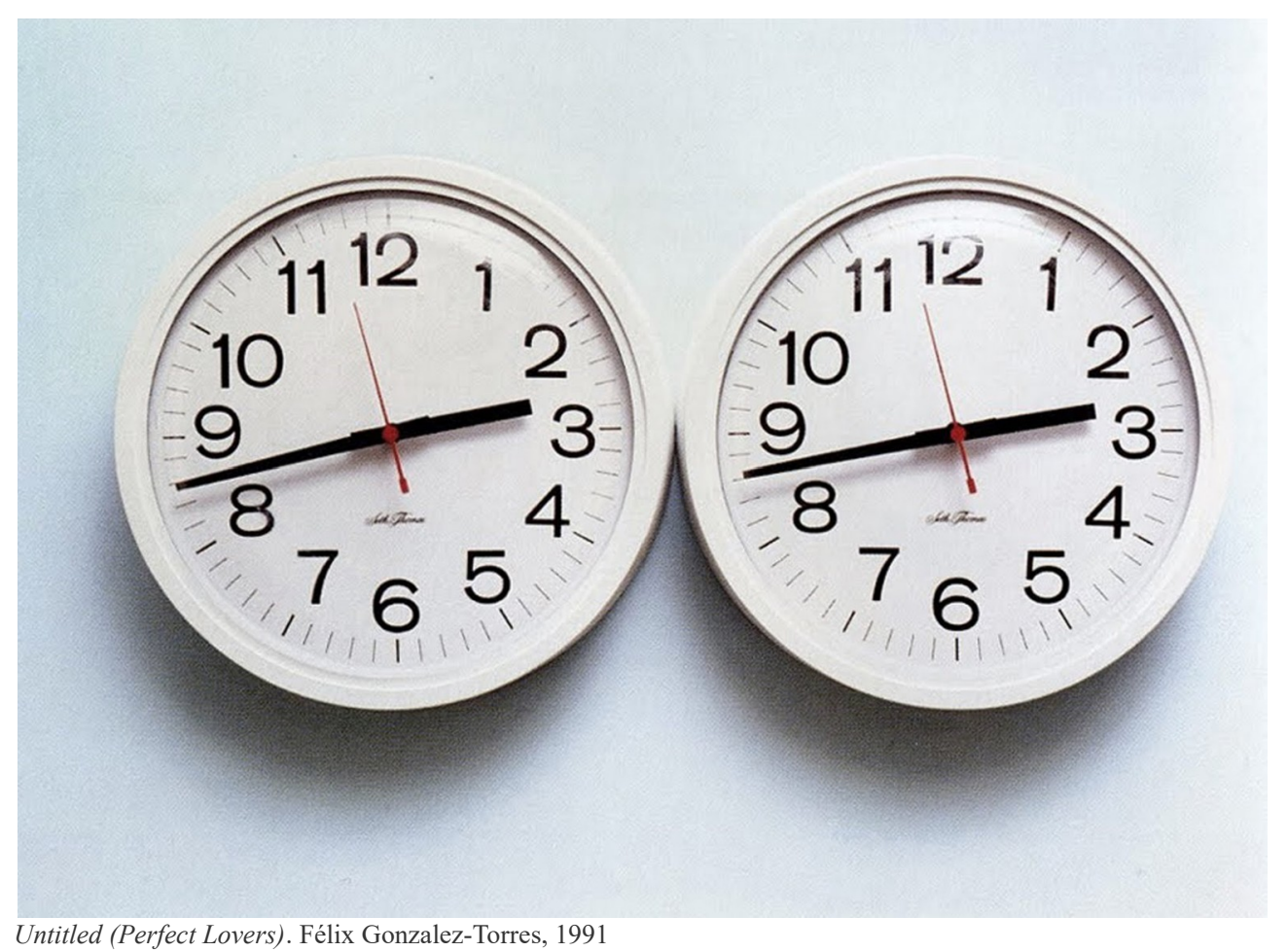

Os relógios de Gonzalez-Torres evocam, segundo a segundo, a ameaça de um presente que pode estancar no tempo se fazendo memória de uma ausência, pois um dos relógios, quando parar, marca uma permanência ao lado daquele que ainda continua o seu ritmo. A angústia sobre qual dos relógios estacará primeiro e qual deles seguirá sua marcha rotineira ao lado do que se tornará o registro de um passado é uma vivência diária à espera do encontro marcado com a catástrofe. Perfect Lovers conta a expectativa latente da falta inevitável que, quando se fizer, questiona a indiferença do tempo cronológico que manterá o seu ritmo no funcionamento solitário da outra peça. A obra figura a rememoração cíclica do passado, que não pode ser esquecido, o qual virá à tona a cada vez que o relógio completar o seu ciclo e passar pela hora exata em que o outro teve seu funcionamento interrompido. Então, nesse curto momento em que os dois relógios novamente se encontram no tempo, reavivando, num átimo, o antigo companheirismo sincrônico, é lançada a possibilidade de uma ressignificação do presente e passado. O fluxo cronológico é atravessado e interrompido pela rememoração e isso acontece, para usar uma referência cara a Benjamin, como um lampejo. ${ }^{22}$ Esse segundo denso, momento permanente da morte do amante, quando acontece, modifica de maneira irreparável a passagem do tempo.

Ao não intitular a obra e expor seu tema entre parênteses - Untitled (Perfect Lovers) -, o artista exibe a estrutura da experiência do tempo ultrapassando os limites do acontecimento particular. A contínua circunferência descrita pelo relógio contém em si o ciclo de vida e morte, amor e perda, que partilhamos. Ela oferece uma organização descontínua do tempo como base da narrativa e configura uma estrutura temporal que 
renuncia ao elemento épico. O ponteiro imóvel do relógio parado arranca, por uma explosão [sprengt $a b$ ] aquele momento da "continuidade histórica" reificada. Ele faz explodir [sprengt auf] a homogeneidade do momento, impregnando-o com o presente. ${ }^{23} \mathrm{~A}$ cada vez que o momento passado, denso de significado, fulgurar reconhecido no presente, há um choque entre os dois relógios no qual o tempo cronológico contínuo é ressignificado. Assim, o acontecimento não é inserido num tempo aditivo que "mobiliza a massa dos fatos para preencher um tempo homogêneo e vazio". ${ }^{24}$

Os relógios que compõem parte da obra de Gonzalez-Torres não oferecem estímulos sensoriais distintos daqueles que os relógios de parede ordinários são capazes de oferecer. Ambos são materialmente indistinguíveis. Somos levados a reagir de maneira diferente diante da obra por qualidades artísticas e não qualidades estéticas, embora as últimas sejam, evidentemente, parte importante na composição de sentido do objeto artístico.

Para Benjamin, que mantém toda a sua filosofia apoiada na linguagem, perceber é um ato de leitura; a ação perceptiva apreende, no conceito, a verdade dos fenômenos (percepção na língua alemã é Wahrnehmung e o verbo perceber é wahrnehmen, ou seja, tomar como verdade). "Os fenômenos subordinam-se aos conceitos. E são estes que dissolvem as coisas nos seus elementos constitutivos". ${ }^{25}$ Assim, por intermédio do conceito, os fenômenos compõem uma configuração de sentido a partir dos fragmentos de verdade que a leitura perceptiva apreende. A base dessa organização teórica da percepção é a adesão de Benjamin ao pensamento romântico de que o mundo deve ser lido. Mas essa leitura não acontece de maneira extensiva, como alguém que percorre as palavras de um texto agregando significados. Ler, no sentido benjaminiano, é construir a partir do dado e o sujeito é o móbil que constrói relações de significado no mundo.

A perda do valor da forma como meio de legitimação da obra de arte desencadeia uma crise no discurso estético tradicional. Livre da objetificação estética, a obra de arte radicaliza a concepção de percepção como leitura na qual a coisa, bem como o contexto no qual ela surge, devem ser interpretados e, com isso, o observador que contempla passivo perde lugar para convocar o observador ativo que compreende a obra a partir de uma estrutura constelar de sentido. A crítica benjaminiana ainda tem muito a dizer sobre esse ajuizamento produtivo da obra de arte. E se Benjamin proclama em Rua de mão única o fim da crítica, é só para fazê-la ressurgir sob outra perspectiva.

\section{* Rizzia Rocha é doutoranda em filosodia pela UFMG.}

${ }^{1}$ SCHLEGEL, F. apud MARC, J. O que é estética? São Leopoldo: Unisinos, 1999, p. 17.

${ }^{2}$ A literatura do século XVIII, e mais propriamente do século XIX, está cheia de exemplos, mas Dostoiévski faz uma interessante reflexão sobre o assunto por meio da personagem Nastácia 
Filippovna em O idiota. A personagem, que perde a família na infância e é criada por um rico fazendeiro, é mantida numa casa isolada numa pequena vila e lá serve ao prazer de seu tutor. Ao se tornar adulta, Nastácia segue para Moscou, torna pública as ações de seu tutor e leiloa a si mesma em casamento.

${ }^{3}$ DANTO, A. O descredenciamento filosófico da arte. Belo Horizonte: Autêntica, 2014, p. 43.

${ }^{4}$ Ibidem, p. 46.

${ }^{5}$ BENJAMIN, W. "O autor como produtor". In: BENJAMIN, W. Magia e técnica, arte e política: ensaios sobre literatura e história da cultura. São Paulo: Brasiliense, 1994, p. 120.

${ }^{6}$ DANTO, A. Op. cit., p. 36.

${ }^{7}$ BAUDELAIRE, C. O spleen de Paris: pequenos poemas em prosa. Rio de Janeiro: Imago, 1995, p. 137.

${ }^{8}$ RAMME, N. "A teoria institucional e a definição de arte". In: Revista Poiésis, n. 17 (jul, 2011), pp. 91-103,aqui p. 93.

${ }^{9}$ BELTING, H. O fim da história da arte: uma revisão dez anos depois. São Paulo: Cosac Naify, 2012, p. 327.

${ }^{10}$ PEDROSA, M. "Considerações inatuais". In: PEDROSA, M. Homem, mundo, arte em crise. São Paulo: Perspectiva, 2007, p. 24.

11 BENJAMIN, W. O conceito de crítica de arte no romantismo alemão. São Paulo: lluminuras, 2002, p. 75.

12 Ibidem, p. 59.

${ }^{13}$ Cf. COLI, A. L. A. O projeto da crítica do conhecimento na obra de juventude de Walter Benjamin. 2013. Dissertação (Mestrado em Filosofia). Faculdade de Filosofia e Ciências Humanas, Universidade Federal de Minas Gerais, Belo Horizonte.

${ }^{14} \mathrm{COLI}$, J. O corpo da liberdade: reflexões sobre a pintura do século XIX. São Paulo: Cosac Naify, 2010, p. 13.

${ }^{15}$ NOVALIS apud BENJAMIN, W. O conceito de crítica de arte no romantismo alemão. Op. cit., p. 60.

${ }^{16}$ Ibidem, p. 62.

17 Ibidem, p. 59.

18 Ibidem, p. 63.

${ }^{19}$ Ibidem, p. 60.

${ }^{20}$ Ibidem, p. 77.

${ }^{21}$ DANTO, A. A transfiguração do lugar-comum. São Paulo: Cosac Naify, 2005, p. 151.

22 "É somente como imagem que lampeja justamente no instante de sua recognoscibilidade, para nunca mais ser vista, que o passado tem de ser capturado". BENJAMIN, W. "Tese V". In: LÖWY, M. Walter Benjamin: aviso de incêndio: uma leitura das teses. São Paulo: Boitempo, 2005, p. 62.

${ }^{23}$ BENJAMIN, W. Passagens. Belo Horizonte: UFMG, 2006, p. 516 frag. N 9a, 6.

${ }^{24}$ BENJAMIN, W. “Tese XVII”. In: LÖWY, M. Op. cit., p. 130.

${ }^{25}$ BENJAMIN, W. Origem do drama trágico alemão. Lisboa: Assírio e Alvim, 2004, p. 20. 